\title{
Janus Kinases and Focal Adhesion Kinases Play in the 4.1 Band: A Superfamily of Band 4.1 Domains Important for Cell Structure and Signal Transduction
}

\author{
Jean-Antoine Girault, ${ }^{1}$ Gilles Labesse, ${ }^{2,3}$ Jean-Paul Mornon, $^{2}$ \\ and Isabelle Callebaut ${ }^{2}$ \\ ${ }^{1}$ INSERM U1 14, Collège de France, Paris, France \\ ${ }^{2}$ Systèmes Moléculaires et Biologie Structurale, LMCP, CNRS UMR \\ 7590, Universités de Paris 6 et 7, Paris, France \\ ${ }^{3}$ Centre de Biochimie Structurale, CNRS UMR 9955, INSERM U414, \\ Université de Montpellier 1, Montpellier, France
}

\begin{abstract}
The band 4.1 domain was first identified in the red blood cell protein band 4.1, and subsequently in ezrin, radixin, and moesin (ERM proteins) and other proteins, including tumor suppressor merlin/schwannomin, talin, unconventional myosins VIIa and X, and protein tyrosine phosphatases. Recently, the presence of a structurally related domain has been demonstrated in the $\mathrm{N}$-terminal region of two groups of tyrosine kinases: the focal adhesion kinases (FAK) and the Janus kinases (JAK). Additional proteins containing the 4.1/JEF (JAK, ERM, FAK) domain include plant kinesin-like calmodulin-binding proteins (KCBP) and a number of uncharacterized open reading frames identified by systematic DNA sequencing. Phylogenetic analysis of amino acid sequences suggests that band $4.1 / \mathrm{JEF}$ domains can be grouped in several families that have probably diverged early during evolution. Hydrophobic cluster analysis indicates that the band 4.1/JEF domains might consist of a duplicated module of
\end{abstract}

$\sim 140$ residues and a central hinge region. A conserved property of the domain is its capacity to bind to the membrane-proximal region of the C-terminal cytoplasmic tail of proteins with a single transmembrane segment. Many proteins with band 4.1/JEF domains undergo regulated intra- or intermolecular homotypic interactions. Additional properties common to band 4.1/ JEF domains of several proteins are binding of phosphoinositides and regulation by GTPases of the Rho family. Many proteins with band 4.1/JEF domains are associated with the actin-based cytoskeleton and are enriched at points of contact with other cells or the extracellular matrix, from which they can exert control over cell growth. Thus, proteins with band 4.1/JEF domain are at the crossroads between cytoskeletal organization and signal transduction in multicellular organisms. Their importance is underlined by the variety of diseases that can result from their mutations.

\section{Introduction}

Attachment of proteins to membranes is necessary for the organization of cell structure, providing each cell with its characteristic shape and its capacity for movement. Work during the last decade has demonstrated that protein targeting to the membrane is also critical for signal transduction (1). The activation of a number of signaling pathways begins with the highly regu-

\footnotetext{
Address correspondence and reprint requests to: Dr. JeanAntoine Girault, INSERM U114, Collège de France, 11, place Marcelin Berthelot, 75231 Paris cedex 05, France. Phone: 33 1 442712 61; Fax: 331442712 60; E-mail: girault@infobiogen.fr
}

lated aggregation of specific proteins at the level of the membrane, allowing the initiation of cascades of enzymatic reactions. Thus, the study of the mechanisms responsible for membrane targeting of cytoplasmic proteins has become a fertile area of research. Many proteins have covalently attached fatty acids including palmitate, myristate, and isoprenoid derivatives, which can themselves be inserted in the lipidic bilayer (2). In some cases these interactions are regulated and proteins can cycle from a soluble to a membrane-bound state. Specific protein domains can also interact noncovalently with membrane phospholipids using pleckstrin homology $(\mathrm{PH})$ 
domains, which bind phosphatidylserine polyphosphates (3), or C2 domains, which bind phosphatidylserine in the presence of $\mathrm{Ca}^{2+}(4)$. Membrane targeting of cytoplasmic proteins is also achieved by interaction of specific domains, including PSD-95/Dlg/Zo-1 (PDZ), WHl/EVH1, and death domains, with transmembrane proteins $(5,6)$. SH2 and phosphotyrosine binding (PTB) domains play an important role by interacting with membrane-associated proteins when they are phosphorylated on tyrosine (7). Interestingly, the roles of lipids and proteins in membrane targeting are not separated, since phospholipids can regulate protein-protein interactions directly or indirectly (8). Moreover, some domains can interact with both lipids and proteins. One example is the PH domains that interact with phosphoinositides and with $\beta / \gamma$ subunits of heterotrimeric $G$ proteins $(3,9)$.

The band 4.1 domain is a large $(>300$ residues) and relatively less characterized domain, capable of interaction with several types of proteins including transmembrane proteins, and in some cases with lipids $(10,11)$. This domain was originally identified as the N-terminal chymotrypsin-resistant region of erythrocyte protein band 4.1, which is capable of binding to glycophorin $C(12,13)$. It was then recognized in three related proteins, ezrin, radixin, and moesin (ERM), which also act as linkers between the actin cytoskeleton and the plasma membrane (10). The band 4.1 domain is present in many proteins $(14,15)$ (Fig. 1). The acronym FERM (Four-point-one/Ezrin/Radixin/Moesin) has been suggested to refer to this domain (14). However, recent work has extended considerably the significance of the band 4.1 domain, showing that, despite a low level of sequence identity, significant structural relationships exist between the $\mathrm{N}$-terminal region of focal adhesion kinases (FAK) and Janus kinases (JAK) (15). A relationship between the band 4.1 domain and FAK N-terminal region was also reported independently by means of a different approach (16). In this review, we will use the term band 4.1/JEF (JAK-ERM-FAK) to refer to this domain. We shall summarize the approaches that allowed identification of the relationship between the distant members of the band 4.1 /JEF superfamily and the structural characteristics of this domain. Some features of the various proteins containing band 4.1/JEF domains and of their known partners are reviewed, and their common properties outlined. Finally, we shall indicate the impor- tance of the mutations of these domains in human pathology.

\section{Sequence and Structural Features of the Band 4.1/JEF Domain Superfamily}

The band 4.1 domain has been defined on the basis of sequence similarities easily detected by automatic procedures such as BLAST or FASTA. This allowed the identification of its presence in ERM and proteins such as protein tyrosine phosphatases, talin, and unconventional myosins $(10,14)$. However, the recognition of this domain in the N termini of FAK and JAK (15) was not possible by this approach and required the use of a bidimensional method of sequence analysis called hydrophobic cluster analysis (HCA) $(17,18)$. The sensitivity of HCA within and below the twilight zone (i.e., $\sim 25-30 \%$ sequence identity) originates from its ability to combine sequence comparison with secondary structure prediction. Indeed, the clusters formed by hydrophobic amino acids on the HCA bidimensional plot (Fig. 2) have been shown to correspond mainly to the internal faces of regular secondary structures in globular proteins (19). They constitute two-dimensional (2D) signatures that are much more stable, and therefore recognizable through human expertise, than signatures described from ID sequence only (20). Therefore, at low levels of sequence identity, the method is particularly efficient in detecting similar folds by sorting out true relationships from background noise (18).

The starting point of the analysis was the finding of a close relationship between the $\mathrm{N}$ terminal sequence of FAK and an uncharacterized human gene product termed KIAA0316 (15). This finding was decisive since, although clearly belonging to the FAK group (Fig. 3), the KIAA0316 sequence is a key linker between the FAK group and the band 4.1 domain of talin. In this respect, talin and related sequences form a distinct group intermediate between FAK and classical ERM band 4.1 domains (Fig. 3). On the other hand, the FAK group was also found to be related to the N-terminal sequence of JAKs. This latter group is distinguished by the long sequences that separate conserved blocks in the alignment of band 4.1/JEF domains (Fig. 2a) (15). Such intervening sequences of variable length interfere with the ability of current $1 D$ methods to establish relationships between pro- 


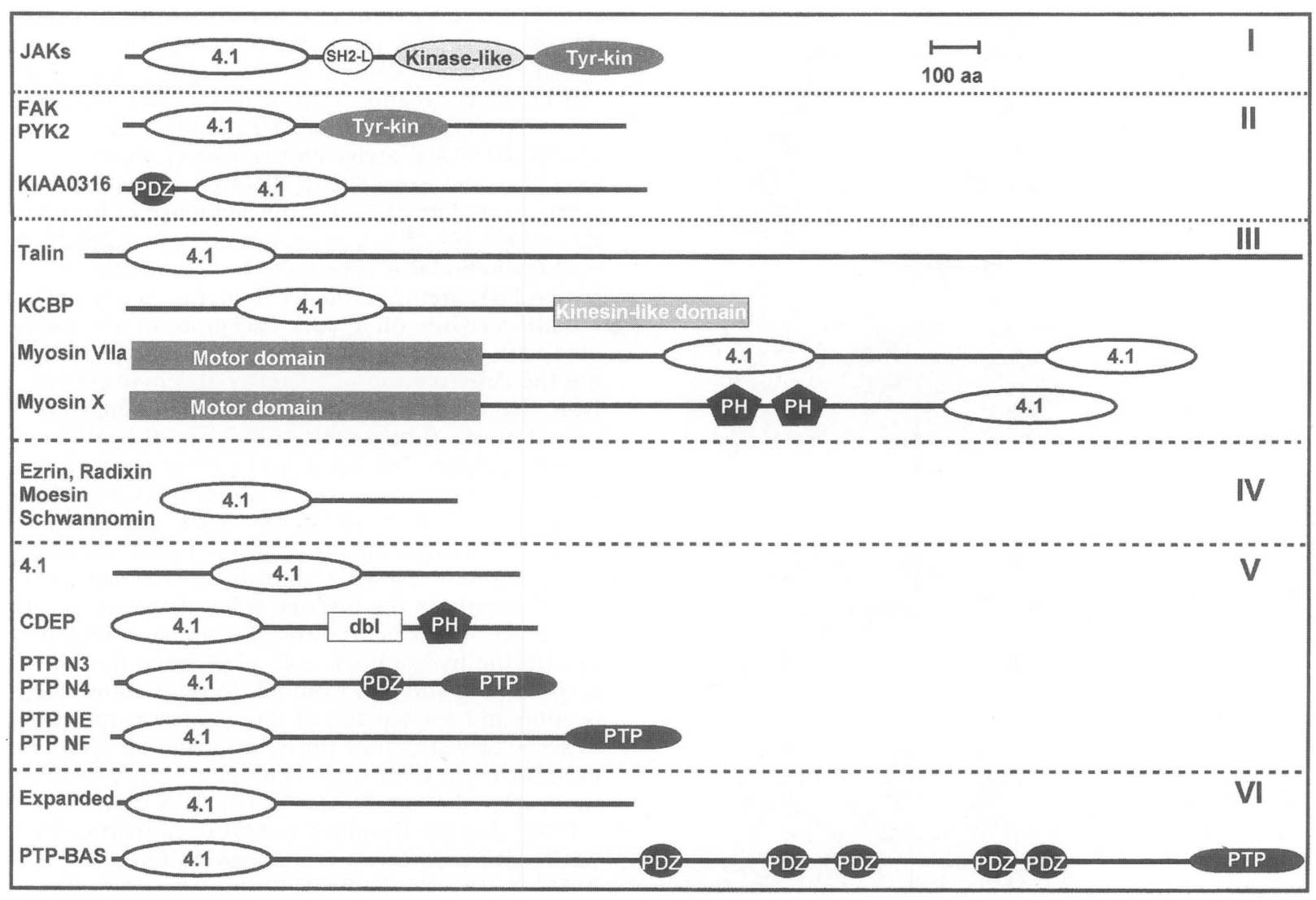

Fig. 1. Schematic domain organization of proteins with band 4.1 JEF domains. Examples of proteins with distinct domain organization are shown in six groups based on the sequence similarities of their band 4.1/JEF domain. Group I: JAK kinases; group II: FAK, PYK2, and KIAA0316, a noncharacterized open reading frame; group III: talin, unconventional myosins, and plant kinesin-like calmodulin binding proteins (KCBP); group IV: the ERM proteins (ezrin, radixin, moesin) and the tumor suppressor merlin/schwannomin; group V: band 4.1, CDEP, and several protein tyrosine phosphatases (PTP); group VI: Expanded, a Drosophila protein, and

teins because of gap penalties that these methods introduce, as they cannot, at least in noniterative procedures, discriminate between secondary structures and loop regions. The presence of a band 4.1-related domain at the $\mathrm{N}$ terminus of FAK was also detected independently by a different approach, using automatic comparison of query sequences to multiple alignements of known domains (16). However, this method could not detect the relationship of band 4.1 with JAK, presumably because of the variable length of sequences between conserved clusters.

As a consequence of this variability, the size of the band $4.1 / \mathrm{JEF}$ domain itself is variable,
PTP-BAS, which have no close relationship with each other or with other proteins in the sequence of their band 4.1/JEF domain. Additional domains include the tyrosine kinase domain (Tyr-kin), the kinase-like domain (kinase-like), a domain structurally related to the Src-homology 2 domain (SH2-L), the PSD95-Dlg-ZOl-homology domain (PDZ), the pleckstrin homology domain $(\mathrm{PH})$, and the protein tyrosine phosphatase domain (PTP). Other characterized regions, including those involved in coiled-coil interactions or in actin binding are not indicated because their sequence and limits are less well defined than those of globular domains.

ranging from $\sim 300$ residues in ERM proteins to $\sim 400$ residues in some JAKs. This large size, as well as the multiplicity of its potential partners, suggests that the band $4.1 / \mathrm{JEF}$ domain could be made up of several modules. A close examination of the HCA plots supports this hypothesis, showing that the band 4.1/JEF domain could consist of a duplicated module (Fig. $2 \mathrm{~b}$; see below). The low sequence identity shared by the two related subdomains indicates that this duplication is an ancient evolutionary event that occurred before the functional specialization of the various band $4.1 / \mathrm{JEF}$ domains. Moreover, in screening databases we were unable to find any 
A

JAK1_HUMAN

FAK1_HUMAN

EZRI_HUMAN
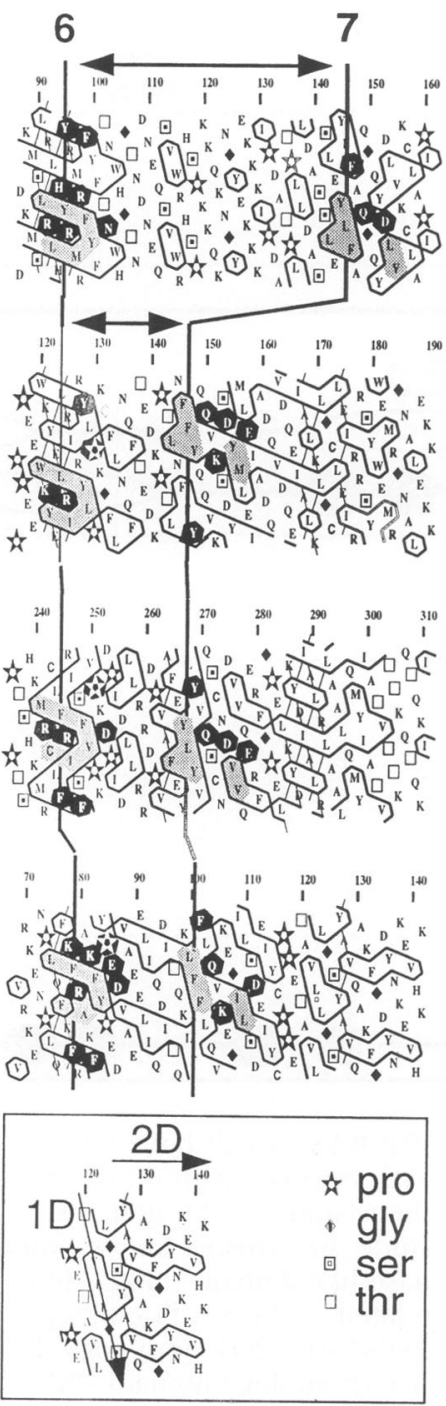

Fig. 2. Structure of the band 4.1/JEF domain (HCA). (A) HCA plots of a conserved region of the 4.1/JEF domain, defined by two highly conserved blocks (blocks 6 and 7), from JAK (JAK1_HUMAN, Swiss-Prot accession number P23458), FAK (FAKl_HUMAN, Swiss-Prot accession number Q05397), and ezrin (EZRI_HUMAN, Swiss-Prot accession number P15311). The sequence of human KIAA0316 (GenBank accession number AB002314) is also shown, as it appears to be a key linker between FAK and classical 4.1 domains. Sequence identities (white on a black background) are associated with cluster similarities (shaded gray), indicating the conservation of a similar 2D environment. Note that the intervening sequences linking conserved blocks (horizontal arrows) are of considerable variable length. The basic principles of HCA plots are indicated in the inset: the amino acid sequence (obliquely from top to bottom and left to right, 1D) is shown on a duplicated $\alpha$-helical net (18). Hydrophobic residues are boxed and form clusters that correspond mainly to the internal sides of regular secondary structures ( $\alpha$ helices and $\beta$ strands), oriented toward the hydrophobic core of globular proteins. Inspection of the plot from left to right allows identification and comparison of those patterns indicative of secondary structure (inset, 2D). Special symbols used for proline (pro), glycine (gly), serine (ser) and threonine (thr) are indicated. (B) HCA plot of the 4.1/JEF domain (residues 1-295) of human ezrin (EZRI_HUMAN, Swiss-Prot accession number P15311). The plot is divided into three parts. The central hinge containing Tyr-145 $\left(\mathrm{Y}^{*}\right)$, a substrate for tyrosine kinases, is set aside to highlight the similarities between the two aligned subdomains (residues 1-132 and 168-295). Secondary structure predictions are shown below the duplicated subdomains. Sequence identities (white on a black background) are associated with cluster similarities (shaded gray), indicating the conservation of a similar 2D environment. Special symbols used for proline, glycine, serine, and threonine are as indicated in panel A.

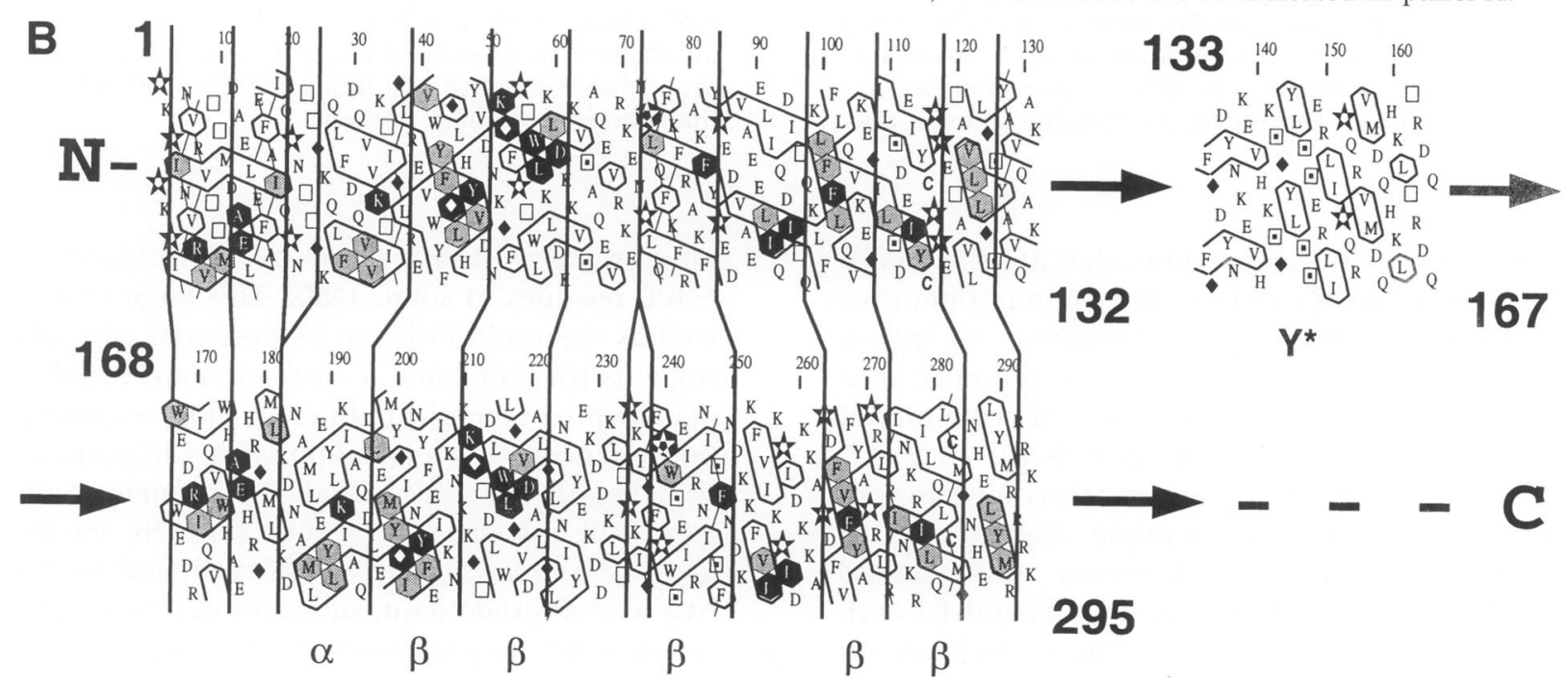




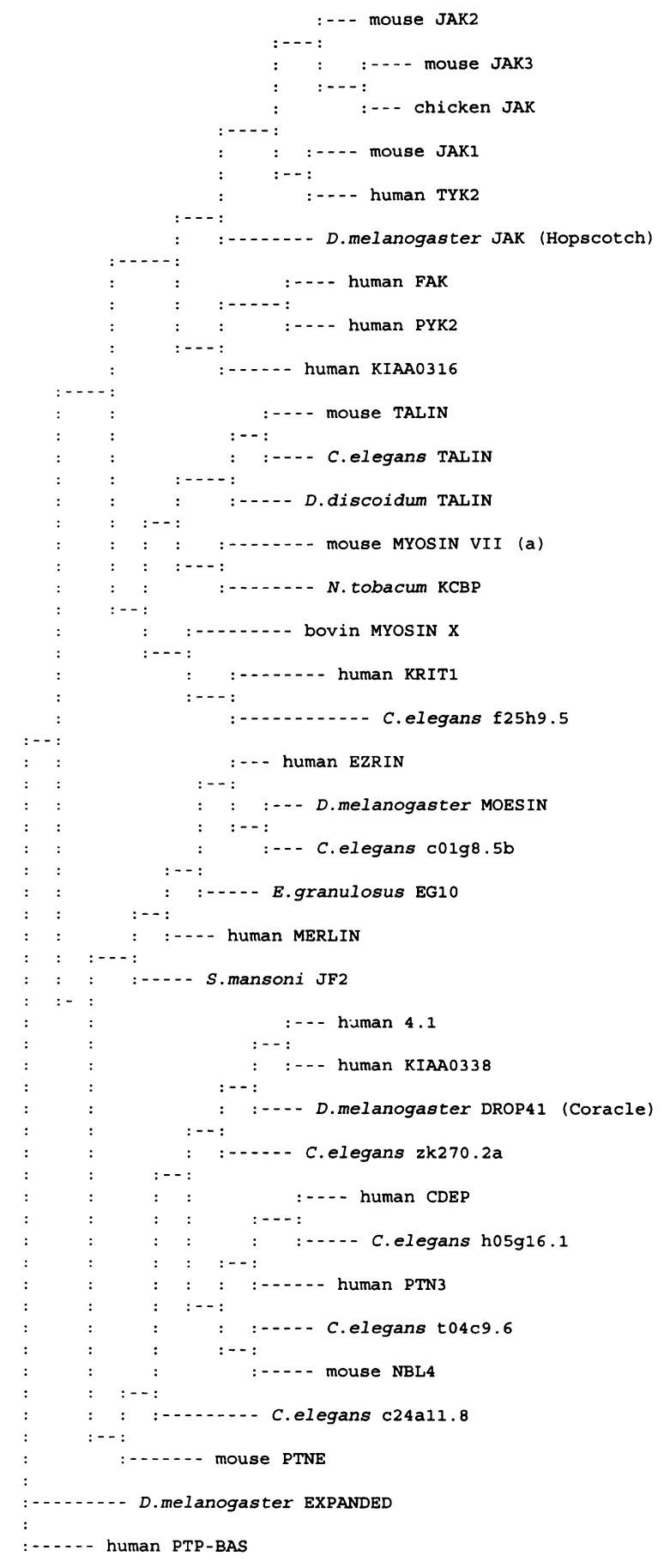

Fig. 3. Hypothetical phylogenetic tree of the band 4.1/JEF domains. Phylogenetic tree based on amino acid sequences aligned following (15) was constructed using the program PROTML in the MOLPHY package (137). Note that the longest intervening sequences (corresponding to loops between conserved blocks) were omitted from the alignment.

occurrence of one of the two subdomains independently, which supports the hypothesis of their ancient origin and suggests a structural in- terdependence between them. Duplications have been described in a number of proteins. They are sometimes easily detected because of a high sequence identity between the subdomairs, whereas in other cases they become apparent only after the experimental determination of the three-dimensional structure.

The band 4.1/JEF domains appear to consist of two structurally similar subdomains of $\sim 130$ residues linked by a short hinge region (block 9) of 30-35 residues, cont $=$ ining an invariant proline residue. The evidence for duplicated subdomains is visible o the HCA plots of human ezrin (Fig. 2b). Sequence conservation (e.g., $\sim 13 \%$ sequence identity in the case of ER/) and $h$ drophobic cluster conservation are observed between the two putative subdomains. The hypothesis of a duplication is further supported by similar secondary structure predictions. Comparison of the sequence of the two putative subdomains highlights short conserved sequence motifs that are predicted to be related to the core structure of the domain or a key conserved function. These motifs, including the stretches $/ x / /$ $\mathrm{g} / \mathrm{n}, \mathrm{w} / \mathrm{x} / \mathrm{d}$ and $/ / / / \mathrm{q} /+$ (where / stands for an hydrophobic residue; + , a positively charged residue; $g$, a glycine residue; $q$, a glutamine residue; $\mathrm{w}$, a tryptophan residue; and $\mathrm{x}$, a variable position) are all associated with predicted buried $\beta$ strands. The evidence for an internal duplication is clear within the 4.1/ERM group and in the case of KIAA0316 (data not shown). Jowever, it is much less conspicuous in the FAK and JAK groups, suggesting that the two subdomains have undergone a divergerit evolution in these tyrosine kinases.

\section{Proteins with Band 4.1/. EF Domains and Their Partners}

Band 4.1 and Related Proteins

Band 4.1 contains a C-terminal actin/spectrin binding-domain and thus acts as a cross-linker between the cortical cytoskeleton and the membrane of erythrocytes, playing a critical role in the characteristic shape of these cells (12). The membrane partners of band 4.1 have been extensively studied. The main anchor site is the short intracellular C-terminal tail of glycophorin $\mathrm{C}$, a small transmembrane protein with a heavily glycosylated extracellular domain. The band 4.1 binding site of glycophorin $\mathrm{C}$ has been mapped precisely $(21,22)$ (Fig. $4 \mathrm{a})$. The $\mathrm{N}$-terminal domain of erythrocyte band 4.1 binds also to the 
anion exchanger of erythrocyte membrane (band 3) (23) and to CD44, first identified as an anchoring site for ERM proteins (see below) (24). The interaction may involve a stretch of arginine residues in band 3 and acidic residues (LEEDY) in band 4.1 (25) (Fig. 4b). Another important partner of the band 4.1/JEF domain in red blood cells is the protein $\mathrm{p} 55$, which contains a $\mathrm{PDZ}$, a SH3, and a guanylate-kinase domain and belongs to the MAGUK (membrane associated-guanylate kinases) family of proteins (21). p55 is capable of binding simultaneously the band 4.1/JEF domain by a short region between its $\mathrm{SH} 3$ and guanylate kinase domains (Fig. 4b) and the $\mathrm{C}$ terminus of glycophorin $\mathrm{C}$ by its PDZ domain $(26,27)$ (Fig. 5a). Thus, a ternary complex between glycophorin C, band 4.1, and p55 may be a basic structural component allowing anchorage of the cortical cytoskeleton to the erythrocyte membrane (Fig. 5a). The sequence in p55 responsible for band 4.1 binding is conserved in Drosophila disc-large protein (Dlg) and its human homologue (H-dlg), which suggests that such interactions have been conserved during evolution (21). The formation of membraneassociated complexes containing band 4.1 is probably highly regulated, since the binding of band 4.1 to glycophorin $C$ is increased by phosphatidylinositol 4,5-bisphosphate (PIP2) (13), whereas $\mathrm{Ca}^{2+} /$ calmodulin reduces its affinity for CD44 (24).

The role of band 4.1 is not restricted to erythrocytes. In fact, a number of different 4.1 proteins with distinct patterns of tissue expression and different intracellular localizations are generated from the same gene, as a result of two different sites of initiation of transcription and multiple alternatively spliced exons $(28,29)$. In addition, several other genes code for related proteins. One of them is an ubiquitously expressed 4.1-G (general protein 4.1) which was identified as a protein interacting with FKBP-13 of the immunophilin family (30). Other as-yet uncharacterized gene products with high sequence similarity to band 4.1 include NBL4 (Novel Band 4.1-Like protein 4) $(31,32$ ) and the open reading frame KIAA0338. In Drosophila, Coracle, a band 4.1-related protein, is enriched in septate junctions between epithelial cells, which are equivalent to tight junctions in vertebrates (33). Last but not least, CEDEP, a recently cloned protein, contains an $\mathrm{N}$-terminal band 4.1/ JEF domain closely related to that of band 4.1, a Rho-guanine nucleotide exchange factor dbl homology domain, and a PH domain (34). Thus, band 4.1 and its close relatives are expressed in many cell types in a wide range of organisms.

Potential transmembrane partners of band 4.1-related proteins, such as anion exchanger or CD44, are also widely expressed. Moreover, the presence of a sequence highly similar to the 4.1 binding site of glycophorin $\mathrm{C}$ has been identified in an otherwise unrelated glycoprotein, paranodin (35) [also termed contactinassociated protein, caspr (36)]. Paranodin is a neuronal glycoprotein highly enriched in the septate-like junctions between myelinating glial cells and axons on both sides of the Ranvier nodes in the central and peripheral nervous system of mammals. Paranodin binds band 4.1 and other proteins with band 4.1/JEF domains in vitro (35 and T. Galvez, L. Goutebroze, J.A. Girault, unpublished results). One probable role of paranodin is to interact with glial proteins on the extracellular side and to provide an anchoring point for the axonal cytoskeleton on the intracellular side, thereby participating in the structure of paranodal junctions. Paranodin is related to a Drosophila protein, neurexin IV, located in septate junctions between epithelial cells during embryogenesis and between glial cells (37). Neurexin IV also has a conserved band 4.1-binding sequence and interacts with Coracle, a Drosophila relative of band $4.1(33,38)$. It has been proposed that other neurexins (I-III), which have some sequence similarity with the band 4.1binding region of glycophorin $C$ and paranodin (Fig. 4a), might also be band 4.1-binding proteins (39). This is an interesting possibility, which should be experimentally tested, since CASK, a MAGUK protein, is also associated with neurexins (40) and binds to band 4.1 (41). Proteins related to band 4.1 are probably attached to a number of transmembrane proteins with different extracellular domains but with a conserved intracellular segment. A tentative consensus binding site for band 4.1, the GNP motif (Glycophorin C, Neurexin IV, Paranodin), can be built by comparing sequences of the three proteins that have been shown to interact with band 4.1 (Fig. 4a). Using the BLAST screening program (42), we were able to find a similar motif in the membrane-proximal C-terminal region of several novel transmembrane proteins (Fig. 4a). These proteins are strong candidates for binding band 4.1 or related proteins. 


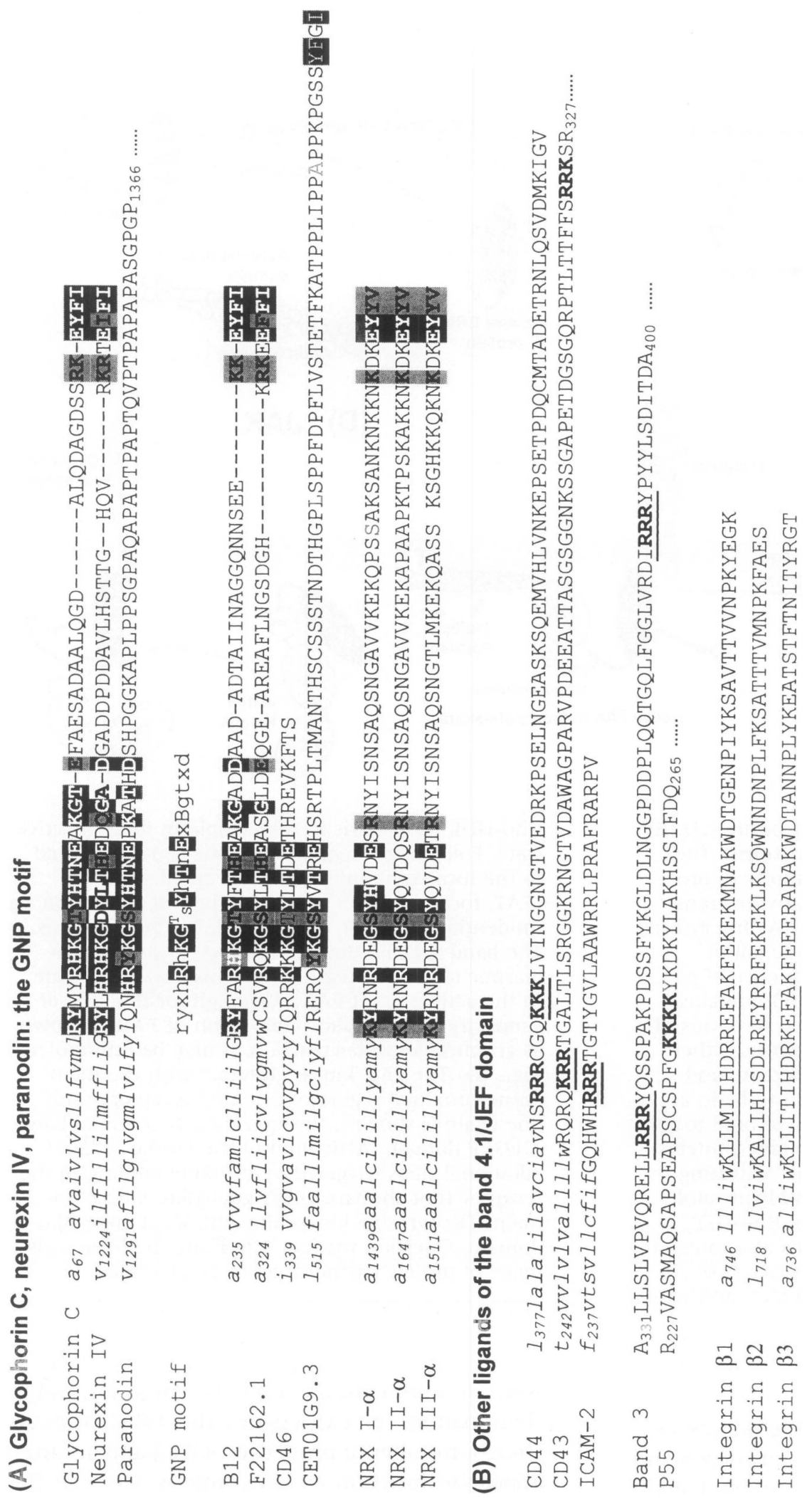

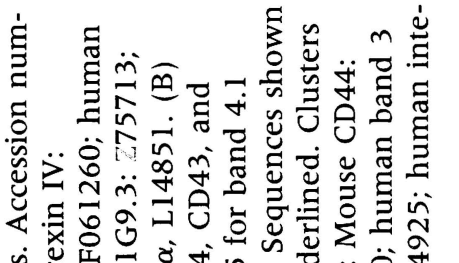

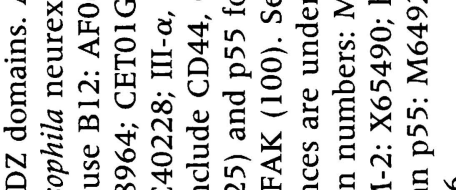

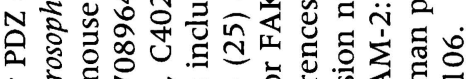

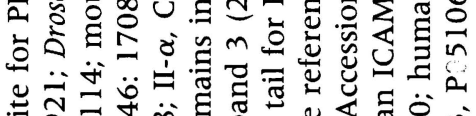

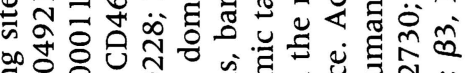

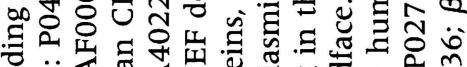

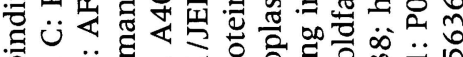

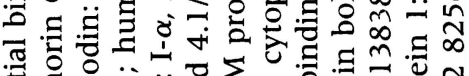

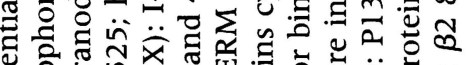
记

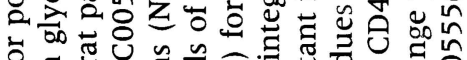

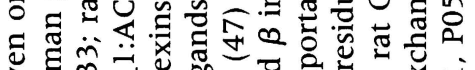

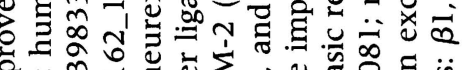
o

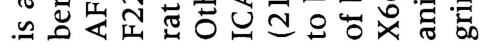

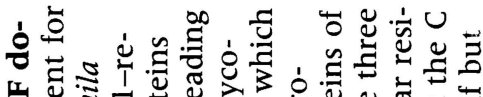

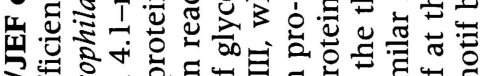

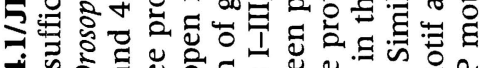

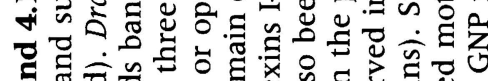

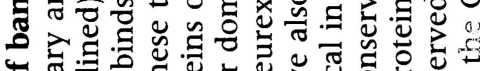
of

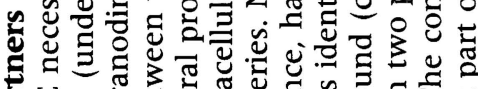

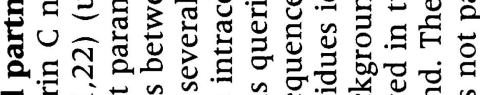

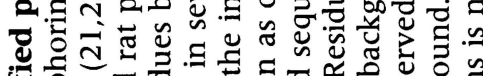

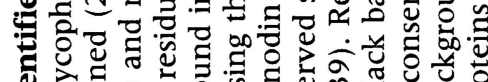

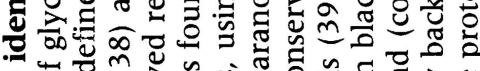

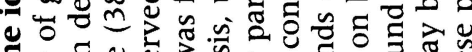

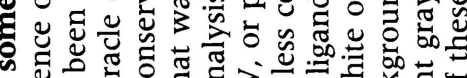

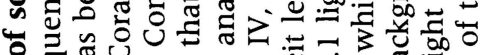

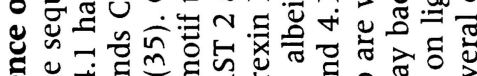

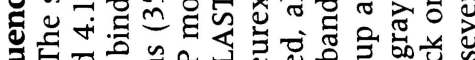

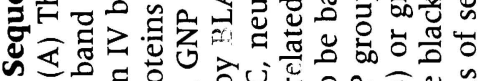

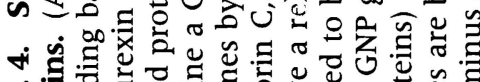

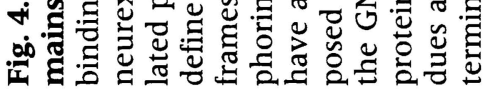



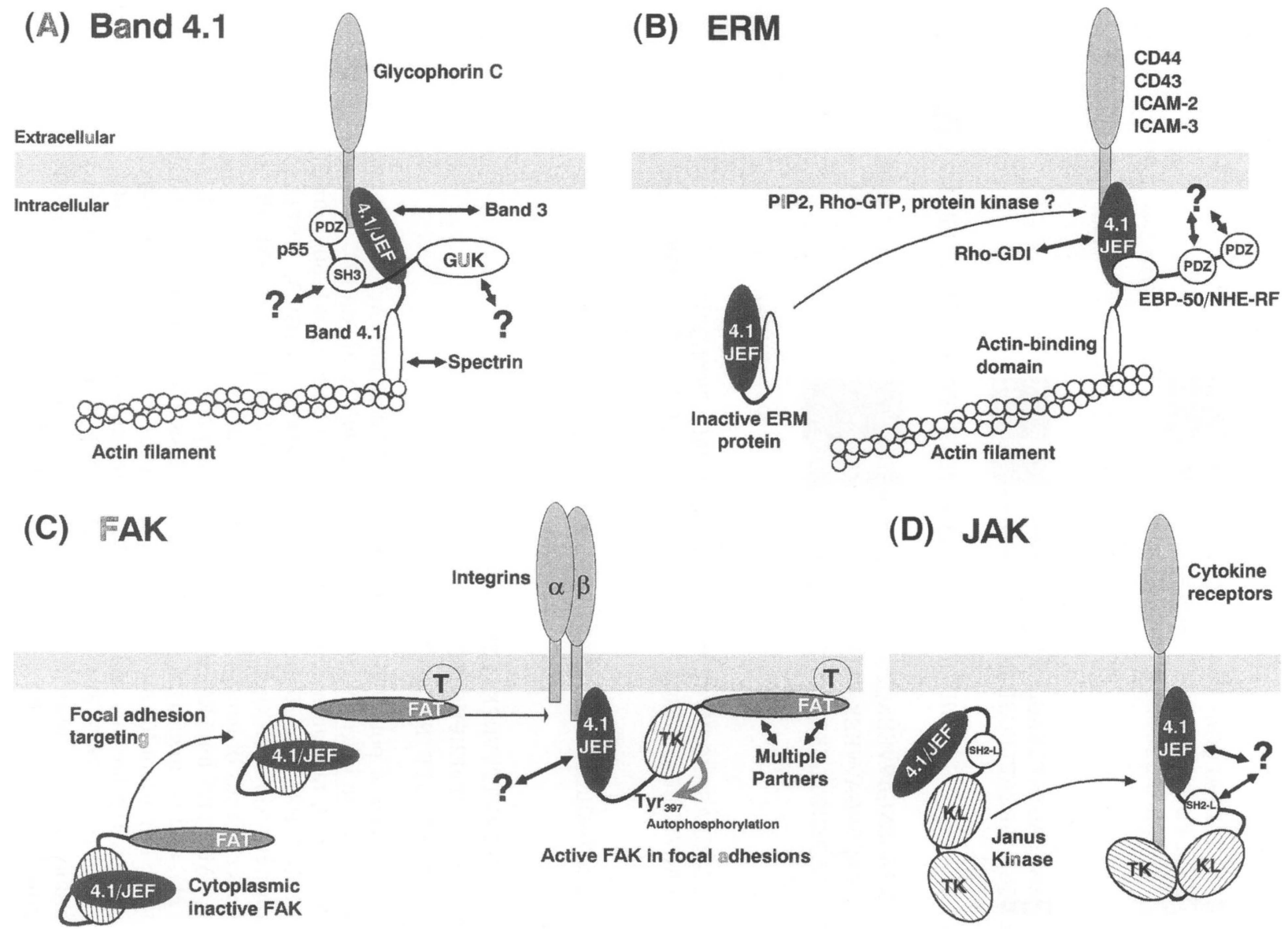

Fig. 5. Functional interactions of band $4.1 / \mathrm{JEF}$ domains with transmembrane proteins. The interactions of four well-studied examples of proteins containing band 4.1/JEF domain with transmembrane proteins are schematized. (A) In erythrocytes band 4.1 binds to the cytoplasmic tail of glycophorin $C$ and with a specific sequence of p55, a protein that also contains $\mathrm{PDZ}$ and $\mathrm{SH} 3$ domains. The $\mathrm{PD} Z$ domain of $\mathrm{p} 55$ binds to the $\mathrm{C}$ terminus of glycophorin $\mathrm{C}$, forming a ternary complex. Other partners of band 4.1 include actin, spectrin, and band 3. (B) ERM proteins are thought to be in a closed state and, following activation, to bind to the cytoplasmic tail of several transmembrane proteins (CD44, CD43, ICAM-2, ICAM-3). This activating step may involve binding to phosphatidylinositol 4,5-bisphosphate (PIP2) and action of Rho-GTP and/or a protein kinase. ERM proteins also interact with EBP-50/NHE-RF, a protein with two PDZ domains associated with $\mathrm{Na}^{+} / \mathrm{H}^{+}$exchanger, and with

\section{The ERM Proteins}

Ezrin, radixin, and moesin are three related proteins of $\sim 80 \mathrm{kDa}$ that have an $\mathrm{N}$-terminal band 4.1/JEF domain and the ability to bind actin $(10,11,43)$. Although there are some sequence differences in their C-terminal moiety (e.g., ab-
Rho-GDI. (C) FAK is in the cytoplasm in an inactive state. Following integrin engagement, it is targeted to the focal adhesions by a C-terminal sequence (FAT, focal adhesion targeting) that interacts with an unidentified target ( $\mathrm{T}$ ) and multiple other proteins. The band 4.1/JEF domain interacts with the cytoplasmic tail of $\beta$ integrins, and this may participate in the activation of FAK. Although for the sake of simplicity the autophosphorylation of FAK is shown as an intramolecular reaction, it may be intermolecular. (D) The JAK kinases interact with the membrane-proximal region of cytokine receptors (only one chain is shown), through their $\mathrm{N}$-terminal band 4.1/JEF domain. Activation of the kinase requires additional steps triggered by cytokine binding to the receptor (not shown). GUK, guanylate kinase domain; TK; tyrosine kinase domain; $\mathrm{KL}$, kinase-like domain. Question marks (?) indicate the likely existence of proteic partners, yet to be identified.

sence of a polyproline stretch in moesin) and in their pattern of expression, the ERM proteins share a number of properties. Like band 4.1 they appear to function as cross-linkers between the actin cytoskeleton and the plasma membrane, and are enriched in microvilli, filopodia, mem- 
brane ruffles, and cell contacts $(10,11,43)$. They bind actin through their $\mathrm{C}$ terminus and, possibly, two additional sites, at the $\mathrm{N}$ terminus and in the band 4.1 domain (res. 281-333) (44). The ERM proteins can interact with CD44, a large and ubiquitous transmembrane glycoprotein, which acts as a receptor for hyaluronic acid, collagen, fibronectin, and serglycin (45) (Fig. 5b). ERM proteins can bind to other transmembrane proteins that have a more restricted pattern of expression such as CD43 and intercellular cell adhesion molecules (ICAM) 2 and $3(46,47)$. ERM proteins also co-localize with the $\mathrm{H}^{+} / \mathrm{K}^{+}$ ATPase and are associated with EBP-50/NHE-RF, a protein with two $\mathrm{PDZ}$ domains that regulates the $\mathrm{Na}^{+} / \mathrm{H}^{+}$exchanger $(48,49)$. In addition, ERM proteins bind to Rho-GDI and reduce its activity, thereby initiating the activation of Rho (50). This observation may be related to the requirement of ERM proteins for the Rho-induced stress fibers formation (51).

ERM proteins have a long $\alpha$-helical region with the ability to form coiled-coil interactions and regions of intramolecular recognition in the $\mathrm{N}$ and $\mathrm{C}$ termini $(52,53)$. These features lead to intra- or intermolecular head-to-tail interactions that are thought to maintain the ERM proteins in a closed conformation as inactive monomers or to provide the basis for dimerization $(11,43)$. Several regulatory factors contributing to the activation of ERM proteins have been reported. ERM proteins contain a conserved tyrosine phosphorylation site that might be involved in the regulation of oligomerization (54). PIP2 binds to the $\mathrm{N}$-terminal band 4.1 domain of ERM proteins and promotes their interaction with CD44 in vitro $(55,56)$. The action of Rho-GTP is necessary for the binding of ERM proteins to CD44 (56). One possible mechanism of action of Rho is the activation of Rho-kinase and the phosphorylation of ERM proteins on a conserved C-terminal threonine, which prevents the head-to-tail interaction (57) (Fig. 5b).

\section{Schwannomin/Merlin}

The gene mutated in neurofibromatosis type 2 (NF2) codes for a tumor suppressor termed schwannomin (58) or merlin (moesin-ezrin-radixin-like protein) (59) that has a high degree of sequence identity with ERM proteins (43\% overall identity with ezrin, $62 \%$ in the band $4.1 \mathrm{~N}$ terminal domain). Schwannomin is co-localized with cortical actin (60-62) and is enriched in membrane ruffles (63). Although it lacks the
C-terminal actin-binding domain of ERM proteins, schwannomin may bind actin by its $\mathrm{N}$ terminal domain (res. 178-367) (64) and one of its splice isoforms (isoform 2) interacts with spectrin by its C-terminal domain (65). Schwannomin also interacts with CD44 (60), microtubules (64), and EBP-50 (48). In Drosophila, homologues of moesin (D-moesin) and merlin/ schwannomin (D-merlin) are both associated with the plasma membrane but the latter appears to be co-localized with the endocytic compartment (66). The precise mechanism by which schwannomin and D-merlin exert their anti-proliferative effects is not known. Loss of function of D-merlin increases cell proliferation and it was demonstrated that all its essential genetic functions reside in its $\mathrm{N}$-terminal 350 amino acids, corresponding to the band 4.1/JEF domain (67). The consequences of NF2 loss of heterozygoty are severe in transgenic mice, leading to the occurrence of a range of highly metastatic tumors (68). Thus, defects in schwannomin and perhaps in other members of the ERM family have an important role in tumor formation and metastasis. Interestingly, Expanded, a Drosophila protein with a divergent band 4.1/JEF domain (Fig. 3) enriched in adherens junctions, also regulates cell proliferation (69). These molecules, like other tumor suppressors associated with cell-cell junctions, such as APC and dlg (70), may control cell proliferation in response to clues provided by cell contacts. It is likely that such controls are very important in regulating cell proliferation during organ development, as suggested by the phenotypes resulting from their mutation in Drosophila $(67,69)$.

\section{Talin and Motor Proteins}

Band 4.1/JEF domains are found in several large proteins closely associated with cytoskeleton. One is talin, a $270-\mathrm{kDa}$ cytoskeletal protein enriched in focal adhesions (71). Talin has multiple actin-binding sites and a band 4.1 domain located near its $\mathrm{N}$ terminus. Talin can dimerize and interact with a number of proteins including $\beta$-integrin cytoplasmic tail, vinculin, and FAK $(71,72)$. Band $4.1 / \mathrm{JEF}$ domains are also four $\mathrm{d}$ in specific isoforms of motor proteins, belonging to the myosin and kinesin groups, that are associated with actin filaments and microtubules, respectively. Myosins VIIa and X are unconventional myosins containing band 4.1/JEF domains located at the $C$ termini (Fig. 1) $(73,74)$. The presence of band 4.1 domains might give these 
proteins a mode of membrane association unique among the unconventional myosins. In addition, myosin $\mathrm{X}$ contains $\mathrm{PH}$ domains, which may also contribute to their membrane attachment. Myosin VIIa is enriched in stereocilia of cochlear and vestibular sensory cells and is necessary for the integrity and function of these cells (74). Band 4.1/JEF domains are also found in a specific group of microtubule-associated proteins related to the kinesin family in plants. Kinesinlike proteins containing band 4.1/JEF domains cloned in Arabidopsis thaliana, Nicotiana tabacum, and Solanum tuberosum have the unique property of binding the $\mathrm{Ca}^{2+}$-calmodulin complex and are termed kinesin-like calmodulin binding proteins (KCBP) (75). These proteins appear to have a role during cell division (76). It can be speculated that the presence of a band 4.1/JEF domain in unconventional myosins VIIa and $\mathrm{X}$ and in (KCBP) may allow their direct association with specific transmembrane receptors, resulting in the movement of membranes relative to actin- or microtubule-based cytoskeleton.

\section{Protein Tyrosine Phosphatases}

Three groups of large protein tyrosine phosphatases (PTPs) contain band 4.1/JEF domains. They all have an $\mathrm{N}$-terminal 4.1 domain and a $\mathrm{C}$ terminal phosphatase domain but their sequences are unrelated between these two domains. These PTPs have been cloned independently by several laboratories and have received different names. One group, characterized by a central PDZ domain, includes two different enzymes: PTPN_3 [PTP Hl (77)] and PTPN_4 [PTP MEG (78)]. The second group also consists of two different enzymes, PTPN_E [PTP36 (79) or PTP-PEZ (80)] and PTPN_F [PTPDl (81) or PTP-RL10 (82) or PTP2E (83)], that have a similar structure but no PDZ domain. The sequences of the band $4.1 / \mathrm{JEF}$ domain of these PTPs are closely related to those of protein 4.1.

In contrast, the band 4.1/JEF domain of a third group of PTP is more divergent (Fig. 3). These phosphatases, known as PTP-BAS (84), PTP-BL (85), PTPIE (86), PTPLl (87), or FAP-1 $(88)$, are very large proteins of $>2400$ r sidues with five central PDZ domains. The human phosphatase FAP-1 interacts with the $C$ terminus of Fas by two of its PDZ domains (PDZ 2 and 4) $(88,89)$. However, the significance of this observation is unclear (90). In general, little is known about the function and regulation of the PTPs with band $4.1 / \mathrm{JEF}$ domains. It is likely that the presence of a band 4.1/JEF domain allows their targeting to specific cell locations by its association with specific membrane proteins. This could result in the enrichment of PTPs in the vicinity of areas of cell contacts and/or in association with cortical cytoskeleton. However, the precise intracellular localization of these enzymes has not been determined.

\section{The FAK Family}

Focal adhesion kinase is a nonreceptor tyrosine kinase substrate for Src and is enriched in focal adhesions $(91,92)$. The knockout of FAK gene is embryonic lethal (93). Its role is thought to include signaling from integrins, turnover of focal adhesion, anti-apoptotic effects of cell contacts with the extracellular matrix, and plasticity in the adult nervous system (94-96). FAK is autophosphorylated in response to integrin engagement or stimulation of a number of $G$ proteincoupled receptors (97). The autophosphorylated tyrosine-397 binds with high affinity Src family kinases that in turn phosphorylate other residues and neighboring proteins, leading to the activation of multiple signaling pathways (98). FAK consists of a central tyrosine kinase domain flanked by a C-terminal domain, which is the site of multiple protein-protein interactions, and an $\mathrm{N}$-terminal domain whose similarity with band 4.1 domain was recently demonstrated $(15,16)$. The region located close to the $\mathrm{C}$ terminus is necessary for the targeting of FAK to focal adhesions (focal adhesion targeting, FAT) (99). Although it does not seem to be involved in this targeting, the $\mathrm{N}$-terminal domain of FAK interacts in vitro with $\beta$ integrins (100).

Autophosphorylation of FAK on Tyr-397, which is located between the band 4.1/JEF domain and the kinase domain, is a critical step in its activation. However, the precise mechanism of this autophosphorylation is not known. It might involve a transient dimerization and an intermolecular phosphorylation, by analogy with growth factor receptors. Alternatively, it could result from the suppression of an intramolecular inhibition, as in the case of Src-family kinases, or from a combination of the two mechanisms (i.e., suppression of intramoiecular inhibition leading to transphosphorylation). Accordingly, deletion of the region corresponding to the band 4.1/JEF domain increases FAK autophosphorylation in vitro $(101,102)$. Moreover, permanent membrane association by fusion of the $\mathrm{N}$ terminus with a trarsmembrane protein results 
in a constitutive activation of FAK (101). These observations are compatible with an intramolecular inhibition by the N-terminal domain (96). Interestingly, neuronal splice isoforms of FAK, which differ from the ubiquitous form by the insertion of short peptides on both sides of tyrosine-397, have a dramatically increased autophosphorylation, suggesting that slight modifications in the peptide joining the kinase domain and the band 4.1/JEF domain and containing the autophosphorylation site have important consequences for activation of the enzyme (103). Thus, FAK is targeted to focal adhesions by its $\mathrm{C}$-terminal region, whereas the $\mathrm{N}$-terminal band $4.1 / \mathrm{JEF}$ domain may contribute to its regulation by interacting with integrins or other as-yet unidentified molecules (Fig. 5c).

To date, the only known tyrosine kinase closely related to FAK is proline rich-tyrosine kinase 2 (PYK2) (104), also named cell adhesion kinase $\beta(\mathrm{CAK} \beta)(105)$, related adhesion focal tyrosine kinase (RAFTK) (106), $\mathrm{Ca}^{2+}$-dependent tyrosine kinase (CADTK) (107), or FAK2 (108). PYK2 displays a high degree of sequence similarity with FAK over most of its sequence. However, the focal targeting properties of PYK2 appear to be repressed in most circumstances (109). Src-family kinases interact with PYK2 following its autophosphorylation on a tyrosine residue (Tyr-402) corresponding to the autophosphorylation site of FAK (110). Although the partners and activation of PYK2 have not been as extensively studied as those of FAK, there are striking similarities and some differences between the two kinases (96). One characteristic of PYK2 is its sensitivity to increased free intracellular $\mathrm{Ca}^{2+}$ $(104,107)$, at least in part mediated by protein kinase $C$ (111-114). The band 4.1/JEF domain most closely related to that of FAK and PYK2 is found in KIAA0316, a predicted open reading frame that contains an $\mathrm{N}$-terminal PDZ domain and a long $\mathrm{C}$-terminal region of unknown function (Figs. 1 and 3; see above).

\section{The JAK Family}

The JAK tyrosine kinases are an important group of nonreceptor tyrosine kinases that associate with the intracytoplasmic region of receptors for a number of cytokines and polypeptidic hormones or growth factors $(115,116)$. These receptors are devoid of intrinsic enzymatic activity, but form homo- or heterooligomers that associate with tyrosine kinases of the JAK family. Each receptor chain interacts preferentially with one or several JAKs. The signaling cascade initiated by these receptors has been extensively studied (see refs. 115,116 for references). Following binding of the cytokine or hormone to the extracellular domain of the receptor, the JAK tyrosine kinases are activated. They phosphorylate the receptor and recruit the STAT proteins, which are unusual transcription factors with $\mathrm{SH} 2$ domains. When phosphorylated on tyrosine by JAKs the STATs dimerize, translocate to the nucleus, and activate transcription of specific genes.

The JAKs contain a number of regions in which the residues are conserved among all the members of the JAK family. These regions have been termed JAK-homology regions $(\mathrm{JH})$ and are numbered $1-7$, starting from the $C$ terminus (by analogy with the $\mathrm{SH}$ domains of the Src family) $(115,116)$. JHl is the tyrosine kinase domain. $\mathrm{JH}_{2}$ is a kinase-like domain that appears to be important for the function of the JAKs but whose precise role is not known. The N-terminal half of the molecule comprising JH3-7 is far less characterized. The region surrounding $\mathrm{JH} 3$ has been shown to possess the structural features of a SH2 domain (117). However, no ligand for this SH2-like domain has yet been identified. The $\mathrm{N}$-terminal region of JAKs, corresponding to the band $4.1 / \mathrm{Jef}$ domain (15), is responsible for their interaction with the receptors and the specificity of this interaction $(115,116)$ (Fig. 5d). Interestingly, the $\mathrm{N}$-terminal limit of the region of Tyk2 necessary for interaction with the interferon $\alpha / \beta$ receptor (118) corresponds to the limit of the band 4.1/JEF domain. Thus, the $\mathrm{N}$-terminal half of JAKs contains two welldefined globular domains, a band 4.1/JEF domain, and a SH2-like domain. The most $\mathrm{N}$ terminal region (corresponding to the first subdomain of band $4.1 / \mathrm{JEF}$ domain and the hinge region, see above) is primarily involved in the binding to the receptor (118). The sequences in the receptor that interact with the JAKs have not been fully identified. The mem . brane-proximal region is critical for the binding of JAKs and a short proline-rich sequence (Box 1) appears to contribute to the specification of the JAK isoform that interacts with the receptor (115,119-121). However, little is known about the regulation of the JAK-receptor interaction and their other partners. Interestingly, one report shows the possibility of an association between JAK2 and FAK (122). 


\section{Common Themes among Band 4.1/ JEF Domains}

This brief overview of the proteins containing band 4.1/JEF domains and of their properties allows us to identify a number of common themes. Obviously, the existence of structural similarities with a low level of sequence identity does not imply that all the functional properties are identical within the superfamily. On the contrary, significant divergence and specialization of the domains are expected. However, it is also likely that some features may be conserved in many members of the superfamily. Thus, information on the most-studied proteins with these domains can be used to generate interesting working hypotheses for the other proteins.

\section{Interactions with the Membrane-Proximal Domain} of Transmembrane Proteins

Many of the proteins with band 4.1/JEF domains interact with the cytoplasmic region of proteins having a single transmembrane segment and an intracellular $\mathrm{C}$ terminus. In most cases (Fig. 4) as well as in the case of cytokine receptors (see above), the interaction involves the membraneproximal region of the transmembrane protein. Some of these proteins (glycophorin C, neurexin IV, paranodin) share a short region of similarity, with a GNP consensus motif also found in other proteins which are good candidates for binding proteins with band 4.1/JEF domains (Fig. 4a). Other proteins (CD44, CD43, ICAM-2, band 3) possess stretches of basic residues (also found in p55) that appear to be important for the interaction with band $4.1 / \mathrm{JEF}$ domains (Fig. $4 \mathrm{~b}$ ). This suggests that there may be several distinct binding sites on band 4.1/JEF domains. The careful study of the interactions between the various band $4.1 / \mathrm{JEF}$ domains and their partners is now required to determine the generality and specificity of these interactions and the structure of the regions involved in binding.

\section{Interactions with Cytoplasmic Proteins}

In addition to intrinsic membrane proteins, band 4.1/JEF domains can bind to a variety of peripheral or cytoplasmic proteins. One particularly interesting example is proteins of the MAGUK family which contain PDZ domains. The ternary complex between protein 4.1, p55, and glycophorin $C$, in which each protein is bound to the two others, has been well characterized in erythrocytes (27). This type of ternary complex can be of general significance since proteins with $\mathrm{PDZ}$ domains, and in some cases guanylate-kinase like domains, are found in association with other proteins which have known or putative binding sites for band 4.1/JEF domains such as neurexins (39-41). Moreover, NHE-RF/EBP-50, a protein interacting with band 4.1/JEF domain of ERMs and schwannomin, possesses PDZ domains associated with $\mathrm{Na}^{+} / \mathrm{H}^{+}$exchanger $(48,49)$ and several proteins with band 4.1 domains contain PDZ domains themselves (Fig. 1). Many of these proteins have additional interaction domains (e.g., actin-binding sites, spectrin-binding sites, SH3; see above). Thus, band $4.1 / \mathrm{JEF}$ domains are likely to participate in multimolecular complexes of potentially unlimited size, forming networks of proteins with multiple interacting domains. Such networks are likely to be the structural framework of many specialized cell regions such as cortical cytoskeleton, focal adhesions, or postsynaptic densities. The exact proteic composition of each network is expected to determine its properties.

\section{Intra- and Intermolecular Interactions of Band 4.1/} JEF Domains

In several cases (e.g., ezrin, radixin, moesin, schwannomin, talin) proteins with band $4.1 / \mathrm{JEF}$ domains have been shown to undergo intramolecular interactions. These interactions involve one site in the band 4.1/JEF domain and one in the $\mathrm{C}$-terminal region and appear to have a functional importance (53): they allow the formation of homomeric complexes of various sizes (54). They also perform a regulatory role by maintaining the protein in a closed inactive state, until a specific stimulus (e.g., phosphorylation by Rhokinase in the case of ERM proteins) "opens" the protein $(43,45)$. It will be very interesting to determine if such principles apply to other proteins with band 4.1/JEF domains, including FAK (96). It is also remarkable that heterotypic interactions have been reported between different proteins with band 4.1/JEF domains. For instance, ezrin, radixin, and moesin (54), talin and FAK (72), and JAK and FAK (122) interact with each other. Not all the sites responsible for these interactions have been mapped precisely. However, it is an intriguing possibility that the same regions involved in intramolecular or homotypic intermolecular interactions are also responsible for heterotypic interactions within the group of proteins with band $4.1 /$ JEF domains. 


\section{Regulation of the Membrane Association of Band} 4.1/JEF Domains

In many cases, the interactions between proteins containing band 4.1/JEF domains and their membrane partners appear to be highly regulated by several factors. The proximity of the membrane may be an important point since binding of a phospholipid (PIP2) increases the affinity of the band 4.1/JEF domain for its transmembrane partner, as demonstrated in the case of band 4.1 and ERM proteins $(13,56)$. A direct binding of PIP2 to ezrin has been demonstrated (55), indicating that some of the band $4.1 / \mathrm{JEF}$ domains contain a lipid binding site. Binding of PIP2 may have several important consequences that are not mutually exclusive: it may promote the opening of the protein containing the band 4.1/JEF domain (see above); it may alter the affinity of another binding site for its proteic partner by an allosteric mechanism; and it may provide an additional anchoring point to the membrane.

A second mechanism of regulation of band 4.1/JEF domains binding to the membrane is the intervention of small GTP-binding proteins of the Rho family. Rho-GTP increases the association of ERMs with CD44 (56). Rho is necessary for FAK activation in response to many stimuli $(123,124)$ and Rho-GTP induces the phosphorylation of FAK and associated proteins (125). The mechanism by which Rho exerts its effects is not precisely known. One possibility is that it activates a serine/threonine kinase (Rho-kinase) that phosphorylates ERM proteins' C-terminus, relieving their intramolecular inhibition (57). It has also been suggested that Rho-GTP might activate a phosphatidylinositol-5 kinase, thereby increasing the levels of PIP2 (45). A strong functional relationship between Rho and some proteins with band 4.1/JEF domains is also indicated by the observation that ERM proteins are required for the effects of Rho-GTP on membrane and cytoskeleton (51). It is noteworthy in this context that the band 4.1/JEF domains of ERMs can associate with Rho-GDI (50) and that CDEP, a novel protein containing a band 4.1/JEF domain, has a domain of homology with Rho-GEF (34).

The properties of proteins with band 4.1/JEF domains can be regulated by phosphorylation. Phosphorylation sites for several serine/threonine or tyrosine kinases have been reported on many of these proteins, and in some cases shown to alter their properties $(57,121,126,127)$. It is possible that different regulatory mechanisms have evolved for each protein with a band 4.1/ JEF domain. However, some properties (e.g., strategic regions for regulation by phosphorylation, presence of a lipid binding site) might be conserved in several, if not all, of these proteins. Determination of the three-dimensional structure of band 4.1/JEF domains will help to address this issue.

\section{Band 4.1/JEF Domains in Multimolecular Complexes Important for Cell Structure and Signal Transduction}

Many proteins with band 4.1/JEF domains are enriched at specific intracellular locations, such as cortical cytoskeleton, focal adhesions, adherens junctions, or septate junctions. As discussed above, they participate in multimolecular complexes that are likely to form large networks important for cell structure. Proteins with band 4.1/JEF domains appear to have two types of roles in these complexes. First, they play a structural role by linking transmembrane proteins to actin cytoskeleton (e.g., band 4.1, ERM, talin). In some specific cases (unconventional myosins VIIa or X and KCBP), they may even participate in actin- or microtubule-dependent movements of macromolecules or membranes. A second type of function in which proteins with band 4.1/JEF domains are involved is signal transduction. Several of these proteins have catalytic domains with protein tyrosine kinase or phosphatase activities. The role of the band 4.1/JEF domains may be to target these enzymes to specific cell locations within structural protein networks and to regulate their activity. Thus, they are placed at strategic cellular locations and generate important messages, in response to cell contacts with other cells or with the extracellular matrix. For example, FAK generates antiapoptotic messages in response to cell adherence (128). In addition, several proteins with band 4.1/JEF domains are tumor suppressors (e.g., schwannomin, Expanded), or are closely associated with such proteins (e.g., dlg), whose physiological role is presumably to harmonize cell growth within tissues by controlling the entry into the cell cycle in response to clues coming from neighboring cells. The JAKs constitute a special case among proteins with band 4.1/JEF domains, as they are not enriched at points of contact with other cells or the extracellular matrix and they do not seem to interact with the cytoskeleton. They may represent a divergent utilization of band $4.1 / \mathrm{JEF}$ domains during evolution, specialized for the con- 
trol of cellular growth in response to secreted polypeptides and not to fixed proteins.

\section{Band 4.1/JEF Domains and Human Pathology}

Mutations in proteins with band 4.1/JEF domains play a role in medicine, giving rise to a variety of diseases that underscore the multiplicity of functions in which these proteins are involved. Mutations in band 4.1 gene are responsible for cases of hereditary elliptocytosis with hemolytic anemia (129). The clinical manifestations result from a defect in the cortical cytoskeleton of red blood cells and are similar to those due to mutations in the genes of two proteins associated with band 4.1: spectrin and glycophorin C. A large variety of mutations in the merlin/schwannomin gene are responsible for NF2, which is characterized by the occurrence of multiple schwannomas and meningiomas (130). Somatic mutations of the NF2 gene are also observed in sporadic schwannomas and mesotheliomas $(131,132)$. Schwannomin is absent in many glial tumors as a result of the combination of a germ-line mutation and a somatic mutation in hereditary cases (NF2), or of two somatic mutations in sporadic cases. It is noteworthy that several mutations of merlin/schwannomin identified in human tumors are missense mutations or short deletions in the band 4.1/JEF domain, emphasizing the functional importance of this domain. The mutation of a third protein with band 4.1/JEF domain, myosin VIIa, is responsible for hereditary deafness in mice and humans (74). Mutations in the myosin VIIa gene result in shaker-1 phenotype in mice and in Usher syndrome type $1 \mathrm{~B}$ in humans. Both diseases include deafness, but patients with Usher syndrome are also blinded by retinitis pigmentosa. It has been hypothesized that myosin VIIa is important for the integrity of the stereocils of the auditory cells and that it may participate in the phagocytosis of photoreceptors by the retinal pigmented epithelium (133). In the case of JAK family, at least one point mutation occurring in the $\mathrm{N}$-terminal region of JAK3 has been reported in humans, resulting in a severe combined immunodeficiency (134). This mutation (Tyr-100 $\rightarrow$ Cys) occurs in one of the most conserved stretches of the band 4.1/JEF domain (block 6), underlining its functional importance. Interestingly, a point deletion in the corresponding position in merlin/schwannomin (Phe-96) has been reported in a case of
NF2 (135). By contrast, a point mutation (Gly$34 \mathrm{l} \rightarrow \mathrm{Glu}$ ) in the Drosophila relative to JAKs, Hopscotch, which results in a dominant gain of function with leukemia-like hematopoietic defects, is located in a loop that appears to be specific for this protein (136).

Thus, although the superfamily of band 4.1/ JEF domains appears to be divergent, the evidence reviewed here suggests that several of their properties have been conserved. We have proposed a number of hypotheses based on this assumption. Experimental approaches, including determination of the three-dimensional structure of representative examples of proteins with this domain, will allow us to test some of these hypotheses.

\section{References}

1. Pawson T, Scott JD. (1997) Signaling through scaffold, anchoring, and adaptor proteins. Science 278: 2075-2080.

2. Casey PJ. (1995) Protein lipidation in cell signaling. Science 268: 221-225.

3. Lemmon MA, Falasca M, Ferguson KM, Schlessinger J. (1997) Regulatory recruitment of signalling molecules to the cell membrane by pleckstrin-homology domains. Trends Cell Biol. 7: 237242.

4. Shao $X G$, Davletov BA, Sutton RB, Südhof TC, Rizo J. (1996) Bipartite $\mathrm{Ca}^{2+}$-binding motif in $\mathrm{C}_{2}$ domains of synaptotagmin and protein kinase $\mathrm{C}$. Science 273: 248-251.

5. Kuriyan J, Cowburn D. (1997) Modular peptide recognition domains in eukaryotic signaling. Annu. Rev. Biophys. Biomol. Struct. 26: 259-288.

6. Sudol M. (1998) From Src homology domains to other signaling modules: proposal of the 'protein recognition code'. Oncogene 17: 1469-1474.

7. Pawson T. (1995) Protein modules and signalling networks. Nature 373: 573-580.

8. Huttelmaier $S$, Mayboroda O, Jarchau T, Jockusch BM, Rudiger M. (1998) The interaction of the cell-contact proteins VASP and vinculin is regulated by phosphatidylinositol-4,5-bisphosphate. Curr. Biol. 8: 479-488.

9. Fushman D, Najmabadi-Haske T, Cahill S, Zheng J, LeVine H, III, Cowburn D.. (1998) The solution structure and dynamics of the pleckstrin homol. ogy domain of $\mathrm{G}$ protein-coupled receptor kinase 2 ( $\beta$-adrenergic receptor kinase 1$)-a$ binding partner of $G_{\beta / \gamma}$ subunits. J. Biol. Chem. 273: 2835-2843.

10. Arpin M, Algrain M, Louvard D. (1994) Membrane-actin microfilament connections: an increasing diversity of players related tc band 4.1. Curr. Opin. Cell Biol. 6: 136-141. 
11. Tsukita S, Yonemura S. (1997) ERM (ezrin/radixin/moesin) family: from cytoskeleton to signal transduction. Curr. Opin. Cell Biol. 9: 70-75.

12. Leto TL, Marchesi VT. (1984) A structural model of human erythrocyte protein 4.1. J. Biol. Chem. 259: 4603-4608.

13. Anderson RA, Marchesi VT. (1985) Regulation of the association of membrane cytoskeletal protein 4.1 with glycophorin by a polyphosphoinositide. Nature 318: 295-298.

14. Chishti AH, Kim AC, Marfatia SM, et al.. (1998) The FERM domain: a unique module involved in the linkage of cytoplasmic proteins to the membrane. Trends Biochem. Sci. 23: 281-282.

15. Girault JA, Labesse G, Mornon J-P, Callebaut I. (1999) The N-termini of FAK and JAKs contain divergent band 4.1 domains. Trends Biochem. Sci. 24: (in press).

16. Schultz J, Milpetz F, Bork P, Ponting CP. (1998) SMART, a simple modular architecture research tool: identification of signaling domains. Proc. Natl. Acad. Sci. U.S.A. 95: 5857-5864.

17. Gaboriaud C, Bissery V, Benchetrit T, Mornon JP. (1987) Hydrophobic cluster analysis: an efficent new way to compare and analyse amino acid sequences. FEBS Lett. 224: 149-155.

18. Callebaut I, Labesse G, Durand P, et al.. (1997) Deciphering protein sequence information through hydrophobic cluster analysis (HCA): current status and perspectives. Cell Mol. Life Sci. 53: 621-645.

19. Woodcock S, Mornon JP, Henrissat B. (1992) Detection of secondary structure elements in proteins by hydrophobic cluster analysis. Protein Eng. 5: 629-635.

20. Poupon A, Mornon JP. (1998) Populations of hydrophobic amino acids within protein globular domains: identification of conserved "topohydrophobic" positions. Proteins (in press).

21. Marfatia SM, Lue RA, Branton D, Chishti AH. (1995) Identification of the protein 4.1 binding interface on glycophorin $\mathrm{C}$ and p55, a homologue of the Drosophila discs-large tumor suppressor protein. J. Biol. Chem. 270: 715-719.

22. Hemming NJ, Anstee DJ, Mawby WJ, Reid ME, Tanner MJA. (1994) Localization of the protein 4.1-binding site on human erythrocyte glycophorins C and D. Biochem. J. 299: 191-196.

23. Lombardo CR, Willardson BM, Low PS. (1992) Localization of the protein 4.1-binding site on the cytoplasmic domain of erythrocyte membrane band 3. J. Biol. Chem. 267: 9540-9546.

24. Nunomura W, Takakuwa Y, Tokimitsu R, Krauss SW, Kawashima M, Mohandas N. (1997) Regulation of CD44-protein 4.1 interaction by $\mathrm{Ca}^{2+}$ and calmodulin-implications for modulation of CD44-ankyrin interaction. J. Biol. Chem. 272: 30322-30328.

25. Jons T, Drenckhahn D. (1998) Identification of the binding interface involved in linkage of cy- toskeletal protein 4.1 to the erythrocyte anion exchanger. $E M B O J$ J 11: 2863-2867.

26. Marfatia SM, Lue RA, Branton D, Chishti AH. (1994) In vitro binding studies suggest a membrane-associated complex between erythroid p55, protein 4.1 and glycophorin C. J. Biol. Chem. 269: $8631-8634$.

27. Marfatia SM, Morais-Cabral JH, Kim AC, Byron O, Chishti AH. (1997) The PDZ domain of human erythrocyte p55 mediates its binding to the cytoplasmic carboxyl terminus of glycophorin C. J. Biol. Chem. 272: 24191-24197.

28. Huang JP, Tang CJ, Kou GH, Marchesi VT, Benz EJ, Jr, Tang TK. (1993) Genomic structure of the locus encoding protein 4.1. Structural basis for complex combinational patterns of tissue-specific alternative RNA splicing. J. Biol. Chem. 268: 3758-3766.

29. Baklouti F, Huang SC, Vulliamy TJ, Delaunay J, Benz EJ, Jr.. (1997) Organization of the human protein 4.1 genomic locus: new insights into the tissue-specific alternative splicing of the premRNA. Genomics 39: 289-302.

30. Walensky LD, Gascard P, Fields ME, et al.. (1998) The 13-kD FK506 binding protein, FKBPl3, interacts with a novel homologue of the erythrocyte membrane cytoskeletal protein 4.1. J. Cell Biol. 141: 143-153.

31. Takeuchi K, Kawashima A, Nagafuchi A, Tsukita S. (1994) Structural diversity of band 4.1 superfamily members. J. Cell Sci. 107: 1921-1928.

32. Kelly GM, Reversade B. (1997) Characterization of a cDNA encoding a novel band 4.1-like protein in zebrafish. Biochem. Cell Biol. 75: 623-632.

33. Fehon RG, Dawson IA, Artavanis-Tsakonas S. (1994) A Drosophila homologue of membraneskeleton protein 4.1 is associated with septate junctions and is encoded by the coracle gene. Development 120: 545-557.

34. Koyano $Y$, Kawamoto $T$, Shen M, Yan WQ, Noshiro M, Fujii K, Kato Y. (1997) Molecular cloning and characterization of CDEP, a novel human protein containing the Ezrin-like domain of the band 4.1 superfamily and the DbI homology domain of Rho guanine nucleotide exchange factors. Biochem. Biophys. Res. Commun. 241: 369375.

35. Menegoz M, Gaspar P, Le Bert M, et al.. (1997) Paranodin, a glycoprotein of neuronal paranodal membranes. Neuron 19: 319-331.

36. Peles E, Nativ $M$, Lustig $M$, et al.. (1997) Identification of a novel contactin-associated transmembrane receptor with multiple domains implicated in protein-protein interactions. $E M B O \mathrm{~J}$. 16: $978-988$.

37. Baumgartner S, Littleton JT, Broadie K, et al.. (1996) A Drosophila neurexin is required for septate junction and blood-nerve barrier formation and function. Cell 87: 1059-1068.

38. Ward RE, Lamb RS, Fehon RG. (1998) A con- 
served functional domain of Drosophila coracle is required for localization at the septate junction and has membrane-organizing activity. J. Cell Biol. 140: 1463-1473.

39. Littleton JT, Bhat MA, Bellen HJ. (1997) Deciphering the function of neurexins at cellular junctions. J. Cell Biol. 137: 793-796.

40. Hata Y, Butz S, Südhof TC. (1996) CASK: a novel dlg/PSD95 homolog with an N-terminal calmodulin-dependent protein kinase domain identified by interaction with neurexins. J. Neurosci. 16: 2488-2494.

41. Cohen AR, Wood DF, Marfatia SM, Walther Z, Chishti AH, Anderson JM. (1998) Human CASK/ LIN-2 binds syndecan-2 and protein 4.1 and localizes to the basolateral membrane of epithelial cells. J. Cell Biol. 142: 129-138.

42. Altschul SF, Madden TL, Schaffer AA, et al.. (1997) Gapped BLAST and PSI-BLAST: a new generation of protein database search programs. Nucl. Acids Res. 25: 3389-3402.

43. Turunen O, Sainio M, Jaaskelainen J, Carpen O, Vaheri A. (1998) Structure-function relationships in the ezrin family and the effect of tumorassociated point mutations in neurofibromatosis 2 protein. Biochim. Biophys. Acta 1387: 1-16.

44. Roy C, Martin M, Mangeat P. (1997) A dual involvement of the amino-terminal domain of ezrin in F- and G-actin binding. J. Biol. Chem. 272: 20088-20095.

45. Tsukita S, Yonemura S. (1997) ERM proteins: head-to-tail regulation of actin-plasma membrane interaction. Trends Biochem. Sci. 22: 53-58.

46. Serrador JM, Alonso-Lebrero JL, Del Pozo MA, et al.. (1997) Moesin interacts with the cytoplasmic region of intercellular adhesion molecule- 3 and is redistributed to the uropod of T lymphocytes during cell polarization. J. Cell Biol. 138: 1409-1423.

47. Yonemura S, Hirao M, Doi Y, Takahashi N, Kondo T, Tsukita S. (1998) Ezrin/radixin/moesin (ERM) proteins bind to a positively charged amino acid cluster in the juxta-membrane cytoplasmic domain of CD44, CD43, and ICAM-2. J. Cell Biol. 140: 885-895.

48. Murthy A, Gonzalez-Agosti C, Cordero E, et al.. (1998) NHE-RF, a regulatory cofactor for $\mathrm{Na}^{+}-\mathrm{H}^{+}$exchange, is a common interactor for merlin and ERM (MERM) proteins. J. Biol. Chem. 273: 1273-1276.

49. Reczek D, Berryman M, Bretscher A. (1997) Identification of EBP50: a PDZ-containing phosphoprotein that associates with members of the ezrin-radixin-moesin family. J. Cell Biol. 139: 169-179.

50. Takahashi K, Sasaki T, Mammoto A, et al.. (1997) Direct interaction of the Rho GDP dissociation inhibitor with ezrin/radixin/moesin initiates the activation of the Rho small $G$ protein. J. Biol. Chem. 272: 23371-23375.
51. Mackay DJG, Esch F, Furthmayr H, Hall A. (1997) Rho- and Rac-dependent assembly of focal adhesion complexes and actin filaments in permeabilized fibroblasts: an essential role for ezrin/radixin/moesin proteins. J. Cell Biol. 138: 927-938.

52. Magendantz M, Henry MD, Lander A, Solomon F. (1995) Interdomain interactions of radixin in vitro. J. Biol. Chem. 270: 25324-25327.

53. Bretscher A, Gary R, Berryman M. (1995) Soluble ezrin purified from placenta exists as stable monomers and elongated dimers with masked C-terminal ezrin-radixin-moesin association domains. Biochemistry 34: 16830-16837.

54. Berryman M, Gary R, Bretscher A. (1995) Ezrin oligomers are major cytoskeletal components of placental microvilli: a proposal for their involvement in cortical morphogenesis. J. Cell Biol. 131: 1231-1242.

55. Niggli V, Andreoli C, Roy C, Mangeat P. (1995) Identification of a phosphatidylinositol-4,5bisphosphate-binding domain in the $\mathrm{N}$-terminal region of ezrin. FEBS Lett. 376: 172-176.

56. Hirao M, Sato N, Kondo T, et al.. (1996) Regulation mechanism of ERM (ezrin/radixin/moesin) protein/plasma membrane association: possible involvement of phosphatidylinositol turnover and Rho-dependent signaling pathway. J. Cell Biol. 135: 37-51.

57. Matsui T, Maeda M, Doi Y, Yonemura S, Amano M, Kaibuchi K, Tsukita S. (1998) Rho-kinase phosphorylates $\mathrm{COOH}$-terminal threonines of ezrin/radixin/moesin (ERM) proteins and regulates their head-to-tail association. J. Cell Biol. 140: 647-657.

58. Rouleau GA, Merel P, Lutchman M, et al.. (1993) Alteration in a new gene encoding a putative membrane-organizing protein causes neurofibromatosis type 2. Nature 363: 515-521.

59. Trofat (1993) A novel moesin-, ezrin-, radixin-like gene is a candidate for the neurofibromatosis 2 tumor suppressor. Cell 72: 791-800.

60. Sainio M, Zhao F, Heiska L, et al.. (1997) Neurofibromatosis 2 tumor suppressor protein colocalizes with ezrin and CD44 and associates with actin-containing cytoskeleton. J. Cell Sci. 110: 2249-2260.

61. Xu L, Gonzalez-Agosti C, Beauchamp R, Pinney D, Sterner C, Ramesh V.. (1998) Analysis of molecular domains of epitope-tagged merlin isoforms in Cos-7 cells and primary rat Schwann cells. Exp. Cell Res. 238: 231-240.

62. Deguen B, Mérel P, Goutebroze L, Giovannini M, Reggio H, Arpin M, Thomas G. (1998) Impaired interaction of naturally occurring mutant NF2 protein with actin-based cytoskeleton and membrane. Hum. Mol. Genet. 7: 217-226.

63. Gonzalez-Agosti C, Xu L, Pinney D, et al.. (1996) The merlin tumor suppressor localizes preferen- 
tially in membrane ruffles. Oncogene 13: 12391247.

64. Xu HM, Gutmann DH. (1998) Merlin differentially associates with the microtubule and actin cytoskeleton. J. Neurosci. Res. 51: 403-415.

65. Scoles DR, Huynh DP, Morcos PA, et al.. (1998) Neurofibromatosis 2 tumour suppressor schwannomin interacts with $\beta$ II-spectrin. Nat. Genet. 18: 354-359.

66. McCartney BM, Fehon RG. (1996) Distinct cellular and subcellular patterns of expression imply distinct functions for the Drosophila homologues of moesin and the neurofibromatosis 2 tumor suppressor merlin. J. Cell Biol. 133: 843-852.

67. LaJeunesse DR, McCartney BM, Fehon RG. (1998) Structural analysis of Drosophila merlin reveals functional domains important for growth control and subcellular localization. J. Cell Biol. 141: 1589-1599.

68. McClatchey AI, Saotome AI, Mercer K, et al.. (1998) Mice heterozygous for a mutation at the NF2 tumor suppressor locus develop a range of highly metastatic tumors. Genes Dev. 12: 11211133.

69. Boedigheimer MJ, Nguyen KP, Bryant PJ. (1997) expanded functions in the apical cell domain to regulate the growth rate of imaginal discs. Dev. Genet. 20: 103-110.

70. Matsumine A, Ogai A, Senda T, et al.. (1996) Binding of APC to the human homolog of the Drosophila discs large tumor suppressor protein. Science 272: 1020-1023.

71. Taylor JM, Richardson A, Parsons JT. (1998) Modular domains of focal adhesion-associated proteins. Curr. Top. Microbiol. Immunol. 228: 135163.

72. Chen H-C, Appeddu PA, Parsons JT, Hildebrand JD, Schaller MD, Guan J-L. (1995) Interaction of focal adhesion kinase with cytoskeletal protein talin. J. Biol. Chem. 270: 16995-16999.

73. Titus MA. (1997) Unconventional myosins: new frontiers in actin-based motors. Trends Cell Biol. 7: 119-123.

74. Mermall V, Post PL, Mooseker MS. (1998) Unconventional myosins in cell movement, membrane traffic, and signal transduction. Science 279: 527-533.

75. Reddy AS, Safadi S, Narasimhulu SB, Golovkin M, Hu X. (1996) A novel plant calmodulin-binding protein with a kinesin heavy chain motor domain. J. Biol. Chem. 271: 7052-7060.

76. Bowser J, Reddy AS. (1997) Localization of a kinesin-like calmodulin-binding protein in dividing cells Arabidopsis and tobacco. Plant J. 12: 1429-1437.

77. Yang Q, Tonks NK. (1991) Isolation of a cDNA clone encoding a human protein-tyrosine phosphatase with homology to the cytoskeletal-associated proteins band 4.1, ezrin, and talin. Proc. Nati. Acad. Sci. U.S.A. 88: 5949-5953.
78. Gu M, York JD, Warshawsky I, Majerus PW. (1991) Identification, cloning, and expression of a cytosolic megakaryocyte protein-tyrosinephosphatase with sequence homology to cytoskeletal protein 4.1. Proc. Natl. Acad. Sci. U.S.A. 88: $5867-5871$.

79. Sawada M, Ogata M, Fujino Y, Hamaoka T. (1994) cDNA cloning of a novel protein tyrosine phosphatase with homology to cytoskeletal protein 4.1 and its expression in T-lineage cells. Biochem. Biophys. Res. Commun. 203: 479-484.

80. Smith AL, Mitchell PJ, Shipley J, Gusterson BA, Rogers MV, Crompton MR. (1995) Pez: A novel human cDNA encoding protein tyrosine phosphatase- and ezrin-like domains. Biochem. Biophys. Res. Commun. 209: 959-965.

81. Moller NPH, Moller KB, Lammers R, Kharitonenkov A, Sures I, Ullich A. (1994) Src kinase associates with a member of a distinct subfamily of protein-tyrosine phosphatases containing an ezrin-like domain. Proc. Natl. Acad. Sci. U.S.A. 91: 7477-7481.

82. Higashitsuji H, Arii S, Furutani M, et al.. (1995) Enhanced expression of multiple protein tyrosine phosphatases in the regenerating mouse liver: isolation of PTP-RL10, a novel cytoplasmictype phosphatase with sequence homology to cytoskeletal protein 4.1. Oncogene 10: 407-414.

83. L'Abbé D, Banville D, Tong Y, et al.. (1994) Identification of a novel protein tyrosine phosphatase with sequence homology to the cytoskeletal proteins of the band 4.1 family. FEBS Lett. 356: 351356.

84. Maekawa K, Imagawa N, Nagamatsu M, Harada S. (1994) Molecular cloning of a novel proteintyrosine phosphatase containing a membranebinding domain and GLGF repeats. FEBS Lett. 337: 200-206.

85. Hendriks W, Schepens J, Bachner D, et al. (1995) Molecular cloning of a mouse epithelial protein-tyrosine phosphatase with similarities to submembranous proteins. J. Cell Biochem. 59: 418-430.

86. Banville D, Ahmad S, Stocco R, Shen S-H. (1994) A novel protein-tyrosine phosphatase with homology to both the cytoskeletal proteins of the band 4.1 family and junction-associated guanylate kinases. J. Biol. Chem. 269: 22320-22327.

87. Saras J, Claesson-Welsh L, Heldin C-H, Gonez LJ. (1994) Cloning and characterization of PTPLl, a protein tyrosine phosphatase with similarities to cytoskeletal-associated proteins. J. Biol. Chem. 269: 24082-24089.

88. Sato T, Irie S, Kitada S, Reed JC. (1995) FAP-1: a protein tyrosine phosphatase that associates with Fas. Science 268: $411-415$.

89. Saras J, Engström U, Góñez LJ, Heldin $\mathrm{CH}$. (1997) Characterization of the interactions between PDZ domains of the protein-tyrosine 
phosphatase PTPLl and the carboxyl-terminal tail of Fas. J. Biol. Chem. 272: 20979-20981.

90. Cuppen E, Nagata S, Wieringa B, Hendriks W. (1997) No evidence for involvement of mouse protein-tyrosine phosphatase-BAS-like Fas-associated phosphatase-1 in Fas-mediated apoptosis. J. Biol. Chem. 272: 30215-30220.

91. Schaller MD, Borgman CA, Cobb BS, Vines RR, Reynolds AB, Parsons JT. (1992) pp $125^{\mathrm{FAK}}$, A structurally distinctive protein-tyrosine kinase associated with focal adhesions. Proc. Natl. Acad. Sci. U.S.A. 89: 5192-5196.

92. Hanks SK, Calalb MB, Harper MC, Patel SK. (1992) Focal adhesion protein-tyrosine kinase phosphorylated in response to cell attachment to fibronectin. Proc. Natl. Acad. Sci. U.S.A. 89: 84878491 .

93. Ilic D, Furuta Y, Kanazawa S, et al.. (1995) Reduced cell motility and enhanced focal adhesion contact formation in cells from FAK-deficient mice. Nature 377: 539-544.

94. Otey CA. (1996) pp $125^{\mathrm{FAK}}$ in the focal adhesion. Int. Rev. Cytol. 167: 161-183.

95. Ilic D, Damsky CH, Yamamoto T. (1997) Focal adhesion kinase: at the crossroads of signal transduction. J. Cell Sci. 110: 401-407.

96. Girault JA, Costa A, Derkinderen P, Studler JM, Toutant M. (1999) FAK and PYK2/CAK in the nervous system, a link between neuronal activity, plasticity and survival? Trends Neurosci. 22: (in press).

97. Richardson A, Parsons JT. (1995) Signal transduction through integrins: a central role for focal adhesion kinase. BioEssays 17: 229-236.

98. Schlaepfer DD, Hunter T. (1998) Integrin signalling and tyrosine phosphorylation: just the FAKs? Trends Cell Biol. 8: 151-157.

99. Hildebrand JD, Schaller MD, Parsons JT. (1993) Identification of sequences required for the efficient localization of the focal adhesion kinase, $\mathrm{ppl} 25^{\mathrm{FAK}}$, to cellular focal adhesions. J. Cell Biol. 123: 993-1005.

100. Schaller MD, Otey CA, Hildebrand JD, Parsons JT. (1995) Focal adhesion kinase and paxillin bind to peptides mimicking $\beta$ integrin cytoplasmic domains. J. Cell Biol. 130: 1181-1187.

101. Chan P-Y, Kanner SB, Whitney G, Aruffo A. (1994) A transmembrane-anchored chimeric focal adhesion kinase is constitutively activated and phosphorylated at tyrosine residues identical to ppl25 $5^{\mathrm{FAK}}$. J. Biol. Chem. 269: 20567-20574.

102. Eide BL, Turck CW, Escobedo JA. (1995) Identification of Tyr-397 as the primary site of tyrosine phosphorylation and $\mathrm{pp} 60^{\text {src }}$ association in the focal adhesion kinase, ppl25 $5^{\mathrm{FAK}}$. Mol. Cell. Biol. 15: 2819-2827.

103. Burgaya F, Toutant M, Studler JM, et al.. (1997) Alternatively spliced focal adhesion kinase in rat brain with increased autophosphorylation activity. J. Biol. Chem. 272: 28720-28725.
104. Lev S, Moreno H, Martinez R, et al.. (1995) Protein tyrosine kinase PYK2 involved in $\mathrm{Ca}^{2+}$. induced regulation of ion channel and MAP kinase functions. Nature 376: 737-745.

105. Sasaki H, Nagura K, Ishino $M$, Tobioka $H$, Kotani $K$, Sasaki T. (1995) Cloning and characterization of cell adhesion kinase $\beta$, a novel protein-tyrosine kinase of the focal adhesion kinase subfamily. J. Biol. Chem. 270: 21206-21219.

106. Avraham S, London R, Fu YG, et al.. (1995) Identification and characterization of a novel related adhesion focal tyrosine kinase (RAFTK) from megakaryocytes and brain. J. Biol. Chem. 270: 27742-27751.

107. Yu H, Li X, Marchetto GS, et al.. (1996) Activation of a novel calcium-dependent protein kinase. J. Biol. Chem. 271: 29993-29998.

108. Herzog H, Nicholl J, Hort YJ, Sutherland GR, Shine J. (1996) Molecular cloning and assignment of FAK2, a novel human focal adhesion kinase, to $8 \mathrm{p} 11.2$-p22 by nonisotopic in situ hybridization. Genomics 32: 484-486.

109. Schaller MD, Sasaki T. (1997) Differential signaling by the focal adhesion kinase and cell adhesion kinase $\beta$. J. Biol. Chem. 272: 25319-25325.

110. Dikic I, Tokiwa G, Lev S, Courtneidge SA, Schlessinger J. (1996) A role for Pyk2 and Src in linking G-protein-coupled receptors with MAP kinase activation. Nature 383: 547-550.

111. Siciliano JC, Toutant M, Derkinderen P, Sasaki T, Girault JA. (1996) Differential regulation of proline-rich tyrosine kinase 2 cell adhesion kinase $\beta$ $\left(\mathrm{PYK} 2 / \mathrm{CAK} \beta\right.$ ) and pp $125^{\mathrm{FAK}}$ by glutamate and depolarization in rat hippocampus. J. Biol. Chem. 271: 28942-28946.

112. Hiregowdara D, Avraham H, Fu YG, London R, Avraham S. (1997) Tyrosine phosphorylation of the related adhesion focal tyrosine kinase in megakaryocytes upon stem cell factor and phorbol myristate acetate stimulation and its association with paxillin. J. Biol. Chem. 272: 1080410810.

113. Raja S, Avraham S, Avraham H. (1997) Tyrosine phosphorylation of the novel protein-tyrosine kinase RAFTK during an early phase of platelet activation by an integrin glycoprotein IIb-IIIaindependent mechanism. J. Biol. Chem. 272: 10941-10947.

114. Soltoff SP, Avraham H, Avraham S, Cantley LC. (1998) Activation of $P_{2 Y 2}$ receptors by UTP and ATP stimulates mitogen-activated kinase activity through a pathway that involves related adhesion focal tyrosine kinase and protein kinase C. J. Biol. Chem. 273: 2653-2660.

115. Pellegrini S, Dusanter-Fourt I. (1997) The structure, regulation and function of the Janus kinases (JAKs) and the signal transducers and activators of transcription (STATs). Eur. J. Biochem. 248: 615-633.

116. Duhé RJ, Farrar WL. (1998) Structural and 
mechanistic aspects of Janus kinases: how the two-faced god wields a double-edged sword. J. Interferon Cytokine Res. 18: 1-15.

117. Bork P, Gibson TJ. (1996) Applying motif and profile searches. Methods Enzymol. 266: 162-184.

118. Richter M, Duménil G, Uzé G, Fellous M, Pellegrini S. (1998) Specific contribution of Tyk2 JH regions to the binding and the expression of the interferon $\alpha / \beta$ receptor component IFNARl. J. Biol. Chem. 273: 24723-24729.

119. Murakami M, Narazaki M, Hibi M, et al.. (1991) Critical cytoplasmic region of the interleukin 6 signal transducer gp 130 is conserved in the cytokine receptor family. Proc. Natl. Acad. Sci. U.S.A. 88: 11349-11353.

120. Nelson BH, Lord JD, Greenberg PD. (1996) A membrane-proximal region of the interleukin-2 receptor gama $c$ chain sufficient for JAK kinase activation and induction of proliferation in $\mathrm{T}$ cells. Mol. Cell. Biol. 16: 309-317.

121. Kaplan DH, Greenlund AC, Tanner JW, Shaw AS, Schreiber RD. (1996) Identification of an interferon-gamma receptor alpha chain sequence required for JAK-1 binding. J. Biol. Chem. 271: 9-12.

122. Zhu T, Goh ELK, Lobie PE. (1998) Growth hormone stimulates the tyrosine phosphorylation and association of p125 focal adhesion kinase (FAK) with JAK2-FAK is not required for statmediated transcription. J. Biol. Chem. 273: 10682-10689.

123. Rankin S, Morii N, Narumiya S, Rozengurt E.. (1994) Botulinum C3 exoenzyme blocks the tyrosine phosphorylation of $\mathrm{pl} 25^{\mathrm{FAK}}$ and paxillin induced by bombesin and endothelin. FEBS Lett. 354: 315-319.

124. Seufferlein T, Rozengurt E. (1995) Sphingosylphosphorylcholine rapidly induces tyrosine phosphorylation of $\mathrm{p} 125^{\mathrm{FAK}}$ and paxillin, rearrangement of the actin cytoskeleton and focal contact assembly-requirement of $\mathrm{p} 21^{\text {rho }}$ in the signaling pathway. J. Biol. Chem. 270: 2434324351.

125. Flinn HM, Ridley AJ. (1996) Rho stimulates tyrosine phosphorylation of focal adhesion kinase, pl 30 and paxillin. J. Cell Sci. 109: 1133-1141.
126. Eder PS, Soong CJ, Tao M. (1986) Phosphorylation reduces the affinity of protein 4.1 for spectrin. Biochemistry 25: 1764-1770.

127. Gould KL, Bretscher A, Esch FS, Hunter T. (1989) cDNA cloning and sequencing of the protein-tyrosine kinase substrate, ezrin, reveals homology to band 4.1. EMBO J. 8: 4133-4142.

128. Hungerford JE, Compton MT, Matter ML, Hoffstrom BG, Otey CA. (1996) Inhibition of pp $125^{\mathrm{FAK}}$ in cultured fibroblasts results in apoptosis. J. Cell Biol. 135: 1383-1390.

129. Delaunay J, Alloisio N; Morle L, et al.. (1996) Molecular genetics of hereditary elliptocytosis and hereditary spherocytosis. Ann. Genet. 39: 209-221.

130. Lutchman M, Rouleau GA. (1996) Neurofibromatosis type 2: a new mechanism of tumor suppression. Trends Neurosci. 19: 373-377.

131. Stemmer-Rachamimov AO, Xu L, Gonzalez-Agosti C, et al.. (1997) Universal absence of merlin, but not other ERM family members, in schwannomas. Am. J. Pathol. 151: 1649-1654.

132. Gutmann DH, Giordano MJ, Fishback AS, Guha A. (1997) Loss of merlin expression in sporadic meningiomas, ependymomas and schwannomas. Neurology 49: 267-270.

133. Hasson T, Mooseker MS. (1997) The growing family of myosin motors and their role in neurons and sensory cells. Curr. Opin. Neurobiol. 7: 615-623.

134. Macchi P, Villa A, Gillani S, et al.. (1995) Mutations of $J a k-3$ gene in patients with autosomal severe combined immune deficiency (SCID). $\mathrm{Na}$ ture 377: 65-68.

135. MacCollin M, Ramesh V, Jacoby LB, et al.. (1994) Mutational analysis of patients with neurofibromatosis 2. Am. J. Hum. Genet. 55: 314320.

136. Luo H, Hanratty WP, Dearolf CR. (1995) An amino acid substitution in the Drosophila hop Tum-1 JAK kinase causes leukemia-like hematopoietic defects. EMBO J. 14: 1412-1420.

137. Saitou N, Nei M. (1987) The neighbor-joining method: a new method for reconstructing phylogenetic trees. Mol. Biol. Evol. 4: 406-425. 